clear distinction between triclinic or monoclinic crystal systems or for the space group to be unambiguously determined.

Acknowledgements. The author is indebted to $\mathrm{Mr} \mathrm{G}$. Walker, Physics and Engineering Laboratory for EDAX analysis and the scanning electron micrograph, to $\mathrm{Mr}$ M. W. Dwyer for the AA analyses, and to Mr K. Palmer, Victoria University of Wellington, for the electron microprobe analyses.

\section{REFERENCES}

Appleman, D. E., and Evans, H. T. Jr. (1973) Job 9214: Indexing and Least-Squares Refinement of Powder Diffraction Data. Nat. Tech. Inf. Service, US Dept. Commerce, Springfield, Virginia, Document PB-216188.

Bell, J. M., Clarke, E. C., and Marshall, P. (1911) NZ Dep. Mines. Geol. Surv. Branch. Bulletin No. 12 (New Series), Wellington, NZ.

Chemistry Division,

Department of Scientific and Industrial Research, Private Bag,

Petone, New Zealand
Deliens, M., and Piret, P. (1980) Bull. Mineral. 103, 17984.

Erd, R. C., Goff, F. E., Cesbron, F. P., and Clark, J. R. (1981) Mineral. Rec. 12, 143-7.

Jambor, J. L. (1976a) Geol. Surv. Canada, Paper, 76-1C, 97-105. (1976b) Can. Mineral. 14, 574-6.

Nickel, E. H., and Berry, L. G. (1981) Ibid. 19, 315-25.

Postl, W. (1978) Mineralogische Notizen aus der Steiermark Mitteilungsblatt Abteilung fur Mineralogie am Landesmuseum Joanneum, 46, 5-22; cited by Schmetzer and Tremmel (1981).

Schmetzer, K., and Tremmel, G. (1981) Neues Jahrb. Mineral. Mh. 443-51.

[Manuscript received 1 August 1983;

revised 13 October 1983]

Copyright the Mineralogical Society

MINERALOGICAL MAGAZINE, SEPTEMBER 1984, VOL. 48, PP. 459-61

\title{
Oriented enstatite inclusions in natural diamond
}

THE sample studied, a twinned diamond, composed of at least four distinct crystals, was collected in the Tibagi River diamond deposits near Telèmaco Borba, Paraná State, Brazil. Under an optical microscope a group of six crystal inclusions was observed; their size ranged between 0.05 and $0.2 \mathrm{~mm}$. All the inclusions were colourless and euhedral, showing different crystal habits, and were identified as forsterite (prismatic and equidimensional crystals) and enstatite (tabular crystals, with $a_{0}=$ $18.17 \pm 0.02 ; \quad b_{0}=8.81 \pm 0.01, \quad$ and $\quad c_{0}=5.17$ $\pm 0.01 \AA$ ). The prismatic forsterite inclusions are oriented along the $\langle 110\rangle$ directions of the host diamond; the main direction of the tabular enstatite crystals are in the same orientation. The identification of the included material, as well as the establishment of the orientation of the inclusions, was obtained by a precession camera using unfiltered Mo radiation. The setting of a selected inclusion under the X-ray beam was achieved by the microradiography technique described by Henriques (1969), and the interpretation of the precession diagrams was by a technique described in an earlier paper (Leite, 1972).

Orientated precession photographs, obtained with the X-ray beam focused on the enstatite inclusions, are shown in figs. 1 (inclusion A) and 3 (inclusion B). In fig. 1 may be seen the $(h k 0)^{*}$ reciprocal plane of enstatite $A$, represented by a circular area limited by very weak Laue streaks (dotted circle), and a misaligned $(h h l)^{*}$ reciprocal plane of the host crystal (dashed line limiting the diamond strong reflections). The picture also shows both reciprocal planes mutually tilted at about $10^{\circ}$ around the [111] diamond axis. The coincidence of the $\overline{4} 20$ and $\overline{1} \overline{1}$ reflection trails of enstatite and diamond, respectively, is, however, nearly perfect, with a misfit smaller than $3^{\circ}$. That coincidence indicates that the (210) enstatite face is set in near parallel orientation in relation to the octahedral layer of the host crystal, as may be seen in the stereogram in fig. 2 . If an exact coincidence could be verified, the mutual orientation of diamond and enstatite should be interpreted as, an epitaxic 

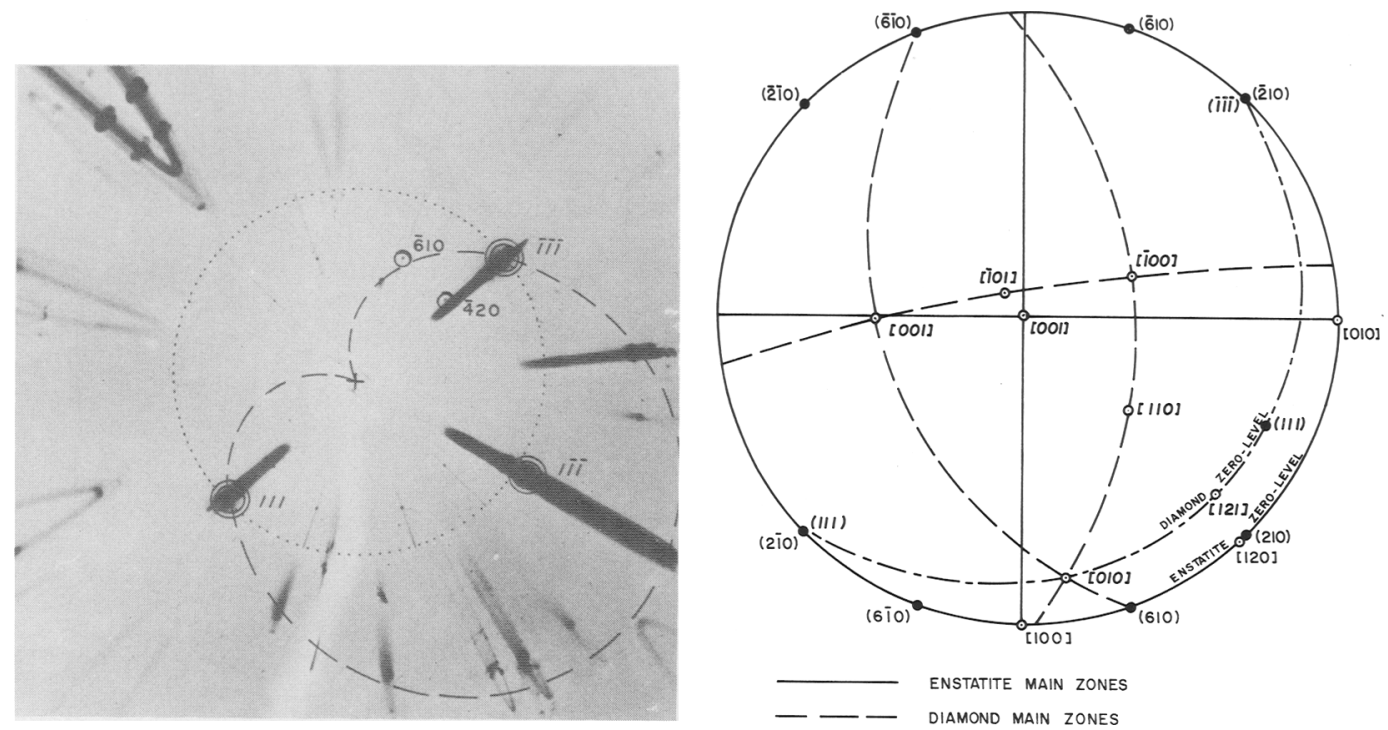

FIGs. I and 2. FIG. 1 (left). Precession orientation photograph of enstatite A and diamond. Unfiltered Mo radiation and $\mu=10^{\circ}$. hkl = enstatite reflections and $h k l=$ diamond reflections. FIG. 2 (right). Stereographic representation of fig. 1 showing the mutual orientation of enstatite and diamond. (hkl) and $[\mathrm{uvw}]=$ enstatite planes and directions; $(h k l)$ and $[u v w]=$ diamond planes and directions.

development, which may be suggested by the lattice correspondences indicated in Table I.

The precession photograph of enstatite B (fig. 3) shows the reflections of the inclusions and of four distinct host diamonds. Three of the latter crystals, including the main diamond (stronger reflections), compose a subparallel association and the fourth diamond is in a twinning position in respect to the other crystals. The figure also shows near parallelism between the $(h k 0)^{*}$ and $(h h l)^{*}$ reciprocal planes of the inclusion and the main diamond, respectively. Those two planes are in fact mutually displaced by about $5^{\circ}$, but clearly visible in the picture is the near coincidence of the $(0 \overline{1} 0)$ and $(1 \overline{1} \overline{1})$ planes of the inclusion and diamond. In this case the epitaxic development may be interpreted by the lattice correspondences suggested in fig. 4 and listed in Table II. The mutual orientation between the inclusion and the twinned crystal (fourth diamond) remains the same as described in the previous case, taking into account the correspondence of the diamond twinning plane and the inclusion mirror plane.

Although the mutual orientation verified between both enstatite inclusions and diamond could be explained in terms of epitaxic relations, some

Table I. Lattice coincldeneas of enstatite A and diamond

\begin{tabular}{|c|c|c|c|c|}
\hline & & Diamond & Enstatita (*) & Misfit \\
\hline Intertaces & & [1]2] & $\{210\}$ & \\
\hline Detrection I & & {$\left[\begin{array}{l}101] \\
0\end{array}\right.$} & [001] & \\
\hline $\begin{array}{l}\text { Jranslation on } I(\stackrel{A}{A}) \\
\text { OIrection II }\end{array}$ & 5.04 & 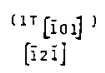 & $\begin{array}{c}5.19(1 T+001]) \\
{[1201}\end{array}$ & $3,4:$ \\
\hline $\begin{array}{l}\text { Translation on II }[\stackrel{a}{A}) \\
\text { Angle between I and II }\end{array}$ & 26.22 & $\underset{90^{\circ}}{(3 T}[\bar{i} z]^{\prime}$ & $\underset{90^{\circ}}{25.37} \underset{[120]}{(1 \mathrm{~T}}$ & 3.48 \\
\hline
\end{tabular}

$1 *$ ) Enstatits transiation (T [Uvw] computed from; $\sigma_{0}=18.22 \AA_{1} b_{0}=8.823 \AA$ and $c_{0}=5.192 \AA$.
Totle II, Lattice coincidences of anstatite $B$ and diamond

\begin{tabular}{|c|c|c|c|}
\hline & of amond & Enstatite $(*)$ & $M 15 f 1 t$ \\
\hline Interfacos & $\operatorname{li} \overline{1} \overline{3}\}$ & $\cos a I$ & \\
\hline Direction I & {$[101]$} & [I02] & \\
\hline $\begin{array}{l}\text { Translation on } I[R] \\
\text { Direction II }\end{array}$ & $\begin{array}{c}20.18{ }^{(4 T}[101]^{\prime} \\
{[110]}\end{array}$ & $\begin{array}{c}20.97(1 T[102])^{\prime} \\
{[001]}\end{array}$ & 4.08 \\
\hline $\begin{array}{l}\text { Transletion on II }(\stackrel{\cap}{A}) \\
\text { Angle between } I \text { and } I I\end{array}$ & $={ }_{60^{\circ}}^{5.04}[110]^{\top}$ & $\begin{array}{c}5.19\left(1 \mathrm{~T}[001]^{3}\right. \\
60.2^{\circ}\end{array}$ & $3.4:$ \\
\hline
\end{tabular}

(*) - Enstatite transletion (T [UVW] computed from: $a_{0}=18.22 \AA_{;} b_{0}=8.829 \AA$ and $e_{0}=5.192 \AA$. 

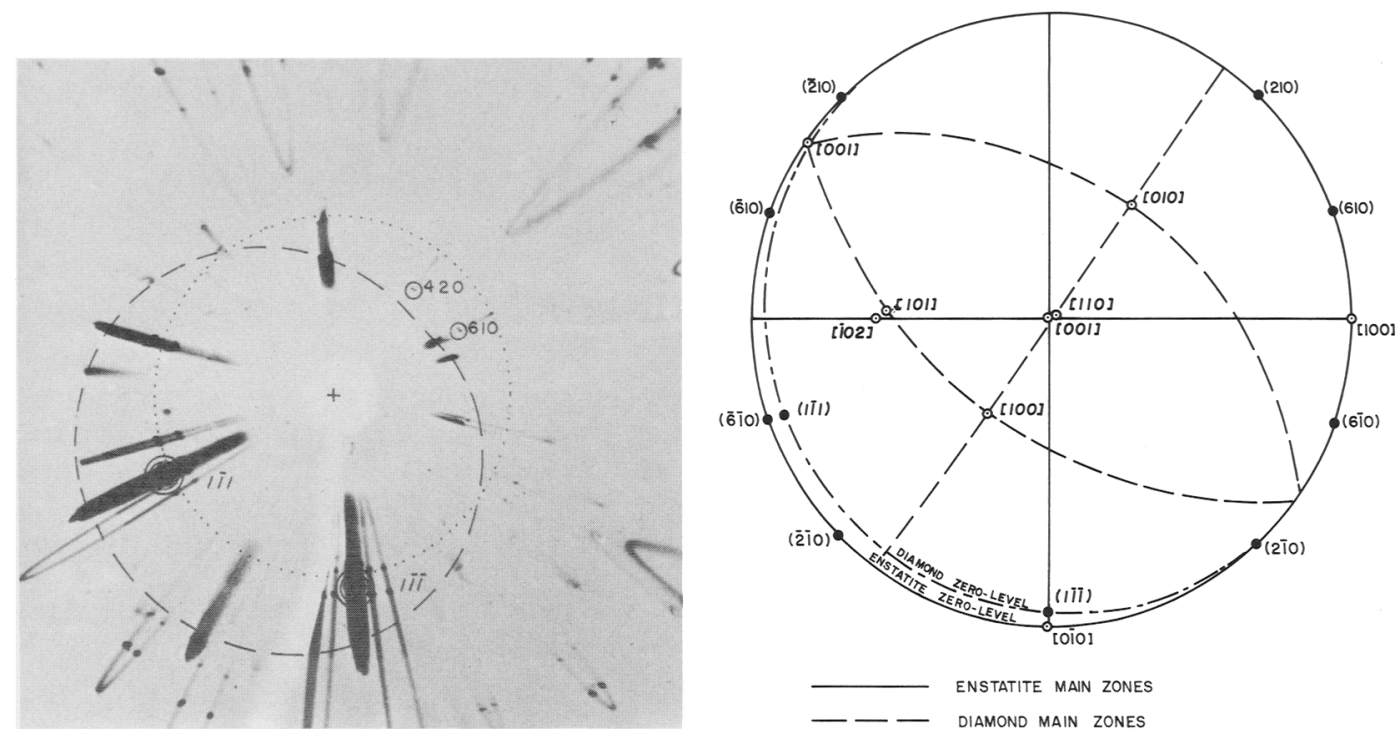

FIGS. 3 and 4. Fig. 3 (left). Precession orientation photograph of enstatite $B$ and diamond. Unfiltered Mo radiation and $\mu=10^{\circ} . \mathrm{hkl}=$ enstatite reflections and $h k l=$ diamond reflections. FIG. 4 (right). Stereographic representation of fig. 3 showing the mutual orientation of enstatite and diamond. (hkl) and [uvw] = enstatite planes and directions; $(h k l)$ and $[u v w]=$ diamond planes and directions.

remarks must be considered before a final conclusion. The disagreements experimentally observed indicate, for example, that the epitaxic conditions were not strictly operating during the growth of the crystals. On the other hand, the morphological significance of the (210) and (010) enstatite planes, observed in the normally developed crystals, suggests that these faces were already formed when the inclusions were incorporated on the diamond octahedral plane. In this case, depending on the initial inclusion size and on the influence of interfacial forces, the final orientation could have arisen by a rotation of the enstatite crystal to a position of minimum energy in respect to the diamond substratum.

\section{REFERENCES}

Henriques, R. (1969) Diam. Conf. Abst. 25. Reading, England.

Leite, C. R. (1972) Bol. Inst. Geoc. USP. 3, 101-60.

[Manuscript received 21 June 1982;

revised 5 December 1983]

(C) Copyright the Mineralogical Society

Instituto de Química, UNESP,

C. R. LeITE

C.P. 174-14.800, Araraquara, SP,

N. BARELLI

Brazil

Instituto Astronômico e Geof ísico, USP,

I. A. SARDELA Av. M. Stefano, 4200-01000, S. Paulo, SP, Brazil 